\title{
Francisco Simch (1877-1937): um economista prático germanófilo no sul do Brasil
}

\author{
Francisco Simch (1877-1937): a Germanophile practical economist in southern Brazil
}

\author{
Luiz Felipe Bruzzi Curi (1) \\ Pedro Hoeper Dacanal (2) \\ (1) Universidade Federal de Minas Gerais \\ (2) Universidade de Lisboa
}

\begin{abstract}
Francisco Rodolpho Simch was an economist and government bureaucrat inserted in the process of international transmission of economic ideas between the nineteenth and twentieth centuries. Born in an area of German colonization in the Brazilian state of Rio Grande do Sul, Simch was a Germanophile intellectual and a public man of regional relevance, in fields such as the teaching of economics, the creation and consolidation of scientific institutions and the exploration of natural resources. His textbook Programa de economia social was inspired by the nineteenth-century German tradition of of approaching and organizing economic knowledge. Seldom present in historical narratives about Brazilian economic thought, Simch's intellectual production reveals specificities concerning the teaching of economics and the peculiar articulation between economic theory and policy.
\end{abstract}

\section{Keywords}

Francisco Simch, international diffusion of ideas, Brazilian economic thought.

JEL Codes B10, B31, N96.

\section{Resumo}

Francisco Rodolpho Simch foi um economista e burocrata governamental inserido no processo de transmissão internacional de ideias econômicas, entre o século XIX e o XX. Nascido em localidade de colonização alemã no Rio Grande do Sul, Simch se tornará um intelectual germanófilo e terá relevância na região no tocante ao estabelecimento do ensino de economia, à criação e consolidação de instituições científicas e à exploração de recursos naturais. Seu livro-texto Programa de economia social inspirou-se na tradição alemã oitocentista de organização do conhecimento econômico. Pouco frequente nas narrativas históricas sobre o pensamento econômico brasileiro, a produção de Simch revela, a partir da perspectiva da difusão internacional das ideias, especificidades relativas à forma de ensino de economia è à peculiar articulação entre a teoria e a política econômica.

\section{Palavras-chave}

Francisco Simch, difusão internacional de ideias, pensamento econômico brasileiro.

Códigos JEL B10, B31, N96. 


\section{Introdução}

Economic science is showing signs of renewed vigour in two of its old homes, Holland and Italy. (...)

But on the whole the most important economic work that has been done on the Continent in this century is that of Germany (...)

Principles of Economics

Alfred Marshall Cambridge (Simch, 1931, p. 447)

Com essa epígrafe, o economista, burocrata e secretário de governo sul-rio-grandense Francisco Rodolpho Simch (1877-1937) abriu a bibliografia da segunda edição de seu Programa de economia social, de 1931. A avaliação positiva que Marshall fazia do trabalho dos economistas alemães do século XIX se confirma na leitura do principal livro deixado por Francisco Simch: na bibliografia, bem como na estrutura temática e formal do texto, a presença da tradição germânica fazia-se notar. Simch utilizou-se de trechos inteiros de manuais de economia alemães para elaborar o referido Programa, que embasava seus cursos na Faculdade Livre de Direito e na Escola Superior de Comércio, ambas em Porto Alegre. Trata-se de um exemplo lapidar das possibilidades colocadas pelo estudo da disseminação internacional do pensamento econômico, no que tange à identificação de processos de apropriação e adaptação de ideias.

A vida pessoal e política de Francisco Rodolpho Simch esteve atrelada ao contexto da transição do século XIX para o século XX no Brasil. Desde o período de sua educação formal, frequentou os ambientes da elite intelectual - como a Escola de Minas de Ouro Preto e a Faculdade Livre de Direito de Porto Alegre - e manteve fortes laços com os integrantes do Partido Republicano Rio-Grandense (PRR), facção política hegemônica no Rio Grande do Sul ao longo da Primeira República. Conquistando espaços institucionais e reconhecimento público, os escritos que publicava tinham repercussão na comunidade. Dados o conteúdo de seus estudos e os cargos que ocupou, é possível que Simch não discordasse se classificássemos a sua trajetória como uma incessante atuação para o "progresso" econômico e intelectual do Brasil.

Essa atuação forneceu bases para que as ideias econômicas de Simch aparecessem na historiografia. Alguns autores mencionam sua produção e suas influências germânicas, porém sem desenvolver com profundidade 
o tema de seu pensamento econômico. É este o caso de Luiz Nogueira de Paula (1942), que descreve resumidamente o perfil da economia política veiculada em diversas instituições brasileiras, entre as quais a Faculdade de Direito de Porto Alegre. É, talvez, o primeiro texto de caráter histórico no qual se faz menção, ainda que breve, à figura de Francisco Simch e a sua orientação teórico-pedagógica germanófila. Mais recentemente, Amaury Gremaud Jr. (1997, p. 111) indica, de passagem, como parte de um panorama geral, que Francisco Simch se utilizara de vários autores alemães em suas aulas de Economia Política no Rio Grande do Sul. Num registro de história política e regional, René Gertz (2002, pp. 168-169) trata da constituição das primeiras faculdades no Rio Grande do Sul, entre elas a Faculdade de Direito de Porto Alegre, e atribui a Francisco Simch um papel relevante nos primeiros anos dessa instituição. Por fim, a atuação de Simch no processo de modernização regional é destacada em trabalho de Zita Possamai (2014) sobre a formação do Museu Julio de Castilhos, do qual Simch foi o primeiro diretor.

Fica claro com essa recapitulação de trabalhos que há uma lacuna a respeito do pensamento econômico de Simch: mencionam-se seu nome, algumas de suas atividades e sua germanofilia, mas não se desdobra o conteúdo de seus textos. Esse quase "esquecimento" por parte da historiografia do pensamento econômico brasileiro não significa, contudo, que as ideias de Simch, bem como seu papel político-institucional, tenham sido irrelevantes no contexto em que escreveu e atuou. É nesse sentido que o prisma da disseminação internacional de ideias permite, conforme aponta José Luís Cardoso (2009), problematizar a própria formação de tradições nacionais de pensamento econômico e rever esquemas de arrumação de autores. Parte-se aqui, portanto, dessa perspectiva como forma de aproximar-se do pensamento econômico de Francisco Simch, dando ênfase aos aportes de origem germânica que orientaram seu projeto intelectual e pedagógico.

Simch não foi, contudo, apenas um acadêmico e pedagogo, mas também um "economista prático", no sentido de ter desempenhado diversas funções fora do âmbito estritamente acadêmico: foi, entre outros cargos, diretor do Museu Julio de Castilhos, chefe do Serviço Geológico e Mineralógico do estado do Rio Grande do Sul e Secretário Estadual de Obras Públicas. Como diretor do museu, tomou a iniciativa de catalogar e expor de forma sistemática a "história natural" do Brasil meridional. Na quali- 
dade de chefe do Serviço Geológico, participou da condução da política econômica, buscando, por exemplo, elevar a oferta de carvão mineral no contexto da Primeira Guerra Mundial. Em ambas as atividades, o denominador comum era a visão da economia como ciência útil, a busca pela interligação entre a esfera concreta da política econômica e o campo mais teórico da ciência econômica.

É essa interligação - ou integração - que Francisco Simch buscou com as sucessivas edições de seu Programa de economia social. Para elaborar o livro-texto, valeu-se de várias fontes germânicas, entre as quais merecem destaque, neste artigo, dois livros de divulgação, escritos por autores pouco canônicos: Richard van der Borght (1861-1926) e Hugo Emil Schober (1820-1882). Mais do que adepto de uma linhagem alemã de pensamento, como o historicismo ou o socialismo de Estado, Simch foi um intelectual que procurou reproduzir, para seu contexto, a maneira alemã oitocentista de discorrer sobre economia e de ensinar a disciplina, da qual Borght e Schober eram tributários e divulgadores. Traços marcantes dessa tradição, veiculada desde as primeiras décadas do Oitocentos, eram a forma descritiva de exposição e o relativismo ao tratar de temas econômicos.

O principal sistematizador dessa linhagem foi Karl Heinrich Rau (17921870), professor da Universidade de Heidelberg, cujo Lehrbuch der politischen Ökonomie (Manual de economia politica) foi reeditado diversas vezes, inclusive postumamente, dos anos de 1820 aos anos de 1870. Rau não foi exatamente um adepto do historicismo alemão, mas o caráter descritivo de seu livro-texto, bem como a articulação entre os fatos da empiria e as questões teóricas, torna sua produção em economia bastante distinta dos tratados oitocentistas britânicos, por exemplo. Do ponto de vista da organização dos temas, o costume era dividir as matérias econômicas em três campos, os quais recebiam, em geral, um volume cada: Volkswirtschaftslehre (economia teórica); Volkswirtschaftspolitik (política econômica) e Finanzwissenschaft (ciência das finanças públicas) (Tribe, 1988, p. 100; Hagemann; Rösch, 2012, p. 197). Simch efetivamente inspirou-se nessa linhagem, traduzindo e fazendo adaptações que tornam seu texto original, ao colocarem-no em sintonia tanto com os manuais germânicos quanto com situações mais concretas da política econômica local.

Este artigo busca, dessa forma, fazer uma reconstituição histórica do pensamento econômico de Francisco Simch, a partir do prisma de suas assimilações germânicas e do contexto sociopolítico em que atuou. As fon- 
tes primárias utilizadas são: obras de Simch (publicadas de 1912 a 1934); livros-texto alemães aos quais Simch teve acesso (presentes na Seção de Obras Raras da Biblioteca da atual Faculdade de Direito da Universidade Federal do Rio Grande do Sul); Relatórios oficiais redigidos por Simch; e diversas edições de jornais da época, principalmente A Federação.

\section{Modernização econômica e institucional no Rio Grande do Sul da Primeira República}

A economia gaúcha na Primeira República foi marcada por um processo de diversificação, com o desenvolvimento industrial articulado ao crescimento da produção agropecuária. No fim do período imperial, ainda predominava a pecuária de corte da Campanha, articulada aos circuitos comerciais brasileiros, porém já se verificava uma incipiente diversificação interna no estado, proporcionada pelas zonas de colonização alemã e italiana na Serra (Fonseca, 1989, p. 40; Love, 1971, pp. 20-25). A importância da imigração, em especial alemã, para a industrialização gaúcha é inegável, muito embora não se queira com essa afirmação corroborar a ideia de que o imigrante tenha desempenhado papel "heroico", como quer a historiografia ligada às comemorações de efemérides da presença imigrante no sul do país. No geral, o imigrante manteve-se ausente do setor mais dinâmico da economia sul-rio-grandense até o início do século $\mathrm{XX}$ : as charqueadas, das quais o setor fabril ligado à imigração só industrializava os resíduos (Lagemann, 1980).

Na perspectiva política do PRR, que se tornaria praticamente hegemônico entre 1893 e 1940 - estando no poder ao longo de todo o processo de diversificação e industrialização -, o republicanismo e o positivismo eram considerados sinônimos: em 1883, a capa dos Anais do Congresso Republicano já registrava o lema "ordem e progresso". O jornal A Federação tornou-se o meio de divulgação dessas ideias republicanas de inspiração positivista, bem como da propaganda abolicionista, e posteriormente funcionou como uma espécie de diário oficial dos governos do PRR. ${ }^{1} \mathrm{O}$ Estado era visto pelos positivistas como produto de uma sociedade já evoluída, como o cérebro dessa sociedade, ao qual caberia um papel de direção e $1 \bigcirc$ jornal foi fundado por republicanos, como Julio de Castilhos, no início da década de 1880, e publicado a partir de 1884 . 
organização. Dessa maneira, o positivismo abria uma brecha para a defesa da intervenção estatal bem maior do que o liberalismo tradicional. E usando de tal intervencionismo, a elite republicana veio a implantar no Rio Grande do Sul tanto uma tributação relativamente progressiva quanto melhorias na educação. Essas medidas faziam parte do ideal positivista de conciliação de classes, já que no estado positivo não deveria haver mais antagonismo entre as classes - e a educação deveria preparar as massas para esse objetivo (Fonseca, 1989, p. 54 e p. 65; Love, 1971, p. 102).

Nesse contexto da virada do século, modernizaram-se também instituições culturais e acadêmicas, em especial o ensino superior, o qual foi estruturado no RS, como também no restante do Brasil, a partir de três núcleos: engenharia, medicina e direito. Segundo a classificação étnico-cultural de Gertz (2002, pp. 159-162), a Faculdade Livre de Direito de Porto Alegre, fundada em 1900, teria sido menos germânica que as escolas de engenharia e medicina na mesma cidade - fundadas em 1896 e 1899, respectivamente -, pois entre seus fundadores haveria uma menor parcela de descendentes de alemães. Essa classificação fornece um parâmetro de comparação interessante, mas obscurece traços relevantes da influência intelectual germanófila na Faculdade de Direito, que se deu por meio da atuação de seus professores. Na área de filosofia do direito, por exemplo, Januário Lucas Gaffrée, que não era de origem alemã e atuou nessa faculdade entre 1906 e 1909, foi um especialista em temas germânicos e, no entanto, não é citado por Gertz. Já Germano Hasslocher e Francisco Simch são descritos por Gertz como os dois professores de sobrenome "alemão puro" na Faculdade de Direito de Porto Alegre, mas o autor não analisa as suas contribuições docentes e intelectuais. No caso de Simch, tal contribuição foi duradoura, pois lecionou de 1909 até os anos de $1930 .^{2}$

No início do século, Porto Alegre, assim como outras cidades brasileiras, assistiu à emergência de elites intelectuais locais que procuraram maneiras de modernizar-se. Na época, isso significava promover algum tipo de progresso regional e nacional, mas, sobretudo, inaugurar novos modos de viver e de imaginar a realidade, pautados por padrões de consumo importados da Europa. Era a belle époque, momento de efervescência para as elites urbanas que se pautavam, cada vez mais, por ideais de progresso social harmônico, apoiando-se nos novos paradigmas intelec2 Hasslocher foi cofundador da faculdade, sua atuação, no entanto, durou somente até 1902, quando se elegeu deputado federal. 
tuais e científicos, consubstanciados em instituições disseminadoras de tais imaginários (Possamai, 2014, pp. 368-369). Esse foi o momento da fundação e reforma de diversos museus no Brasil: foi a chamada "era dos museus" (Schwarcz, 1993, pp. 87-90). Foram criados, no Rio Grande do Sul desse contexto, o Museu Estadual Julio de Castilhos, o Arquivo Público e a Biblioteca Pública. A instalação dessas instituições pode ser vista como uma tentativa de fomentar uma sociedade modernizada, em moldes científicos. O museu estadual, em especial, encaixava-se nesse perfil de inciativa, devido às diretrizes dadas por Simch, seu primeiro diretor (Possamai, 2014, pp. 370-371). No Relatório que elaborou em 1910, como diretor do museu, Simch expôs o que considerava ser a finalidade do estabelecimento: "reunir de fórma systematica e completa as amostras de todos aquelles elementos oriundos do Rio Grande do Sul e susceptiveis de apuração industrial." ${ }^{3} \mathrm{O}$ museu deveria ser, acima de tudo, um local para estudo e exposição dos recursos naturais do Rio Grande do Sul, sendo o principal critério curatorial a "utilidade econômica" dos espécimes minerais, vegetais e animais, que deveriam ser coletados, classificados e expostos. Essa concepção de museu se articulava a um projeto de entendimento da economia local. No dizer de Simch: "As condições economicas de uma região dependem, de modo absoluto, de suas condições naturaes; estas por sua vez são determinadas pela constituição do solo, do clima e da fauna e da flora respectiva." ${ }^{4}$

Essa "ciência natural útil" era parte integrante do que Simch entendia como o campo do conhecimento econômico. Nos moldes da tradição intelectual germânica, a economia teórica estava articulada ao campo amplo da Volkswirtschaftspolitik (política econômica), que incluía essa dimensão do uso econômico dos recursos naturais como um dos seus conteúdos centrais. Sem entrar, ainda, no exame do livro Programa de economia social, vale antecipar que, na parte referente à política econômica, Simch abordava, entre outros temas, a exploração de carvão mineral no Rio Grande do Sul, os desafios e possibilidades envolvidos na atividade mineradora, os sistemas de comunicação e transporte, bem como as dificuldades e possíveis soluções referentes às secas no nordeste brasileiro.

3 Arquivo Histórico do Rio Grande do Sul (AHRS). Secretaria de Obras Públicas. Relatório da secretaria de Estado dos negócios das obras públicas, 1910. p. 24.

4 Arquivo Histórico do Rio Grande do Sul (AHRS). Secretaria de Obras Públicas. Relatório da secretaria de Estado dos negócios das obras públicas, 1910. p. 27. 


\section{Simch: "economista prático" e "intelectual para o progresso"}

Foi dentro do processo histórico esboçado até aqui que a família Simch constituiu-se e ampliou-se, provendo quadros da elite intelectual gaúcha. Francisco José Simch e Ema Wild Simch tiveram seu primeiro filho, o futuro economista Francisco Rodolpho, em 25 de agosto de 1877 na cidade de Santa Cruz do Sul. Nessa mesma cidade, o pai, Francisco José (18511928), ${ }^{5}$ candidatara-se a vereador em 1880 , e sem conquistar uma vaga, restou como suplente. ${ }^{6}$ Pelo interior do estado, trabalhou como agrimensor e integrou a Guarda Nacional, chegando ao ano de 1892 como capitão aliado às tropas republicanas, comandando um batalhão de infantaria na cidade de São Gabriel.7 Em 1895, após a vitória republicana na Revolução Federalista (1893-95), Francisco José já galgava o posto de "chefe da segunda seção da diretoria de obras públicas, terras e colonização da Secretaria de Obras do Estado" e, entre outras funções, intercedia junto ao governo para que a instalação de novos imigrantes se desse em boas condições. ${ }^{8}$ Em 1900, além de ocupar tal cargo público, também era representante da Rio Grande Nord-West-Bahn Gesellschaft ou Estrada de Ferro Noroeste do Rio Grande, sociedade com responsabilidade limitada, formada por um grupo de acionistas, com sede em Berlim (Neumann, 2009, pp. 68-69). ${ }^{9} \mathrm{Em}$ junho de 1901, 21 anos após não conseguir ser eleito vereador em uma pequena cidade do interior, Francisco José Simch estaria junto às figuras mais importantes da política regional, como Castilhos e Borges de Medeiros, participando da comitiva que recepcionou o ministro austríaco Eugenio Kuczynski, em visita oficial a Porto Alegre. ${ }^{10}$ Em novembro do mesmo ano, seria alçado a Coronel da Guarda Nacional. ${ }^{11}$

Com tal pano de fundo familiar - exemplo, em certo sentido, de um processo exitoso de integração e ascensão social de imigrantes no Rio Grande do Sul -, Francisco Rodolfo Simch construirá sua vida em Porto

5 Jornal A Federação (doravante "AF"), 30 ago. 1895, p. 2.

6 Jornal Germania, São Paulo, 28 jul. 1880, p. 1.

7 AF, 7 jul. 1892, p. 1; AF, 19 jul. 1892, p. 2.

8 AF, 5 fev. 1895, p. 2. Ver também Sponchiado (2000, n. 273).

9 AF, 27 fev. 1900, p. 3. F. J. Simch era acionista da empresa, embora minoritário.

10 AF, 28 jun. 1901, p. 2.

11 Diário Oficial da União, 7 nov. 1901, Seção 1, p. 6. 
Alegre. Concluindo seus estudos escolares em 1895, dali parte para Ouro Preto, onde cursaria a Escola de Minas e, para ajudar a custear sua estadia, atuaria como professor no Gymnasio Mineiro, inclusive vindo a lecionar alemão para o jovem Getúlio Dornelles Vargas, conterrâneo que fora a Minas concluir seus estudos escolares (Neto, 2012, pp. 44-47 e 87-88). ${ }^{12} \mathrm{Em}$ 1899, de volta a Porto Alegre, formado "engenheiro geômetra e de minas", Simch inicia-se na vida profissional e logo começa a explorar os arrabaldes da capital e outras cidades em busca de riquezas minerais, vindo a organizar um mapa da constituição geológica de vários pontos do estado e das jazidas de diversos minerais. ${ }^{13}$ De 1902 em diante, o jornal A Federação publicaria artigos científicos e discursos de Simch; o jornal sempre se referia aos integrantes da família Simch de maneira amistosa.

Em 1903, com 26 anos, Simch foi designado diretor do Museu Estadual Julio de Castilhos e também iniciou o curso superior de direito na recém-criada Faculdade Livre de Direito de Porto Alegre; além disso, lecionava no Gymnasio do Rio Grande do Sul. ${ }^{14}$ Em 1906, no quarto ano de direito, foi "aprovado com distinção" na cadeira "economia política", na qual seu colega Getúlio Vargas foi também aprovado. ${ }^{15}$ No ano seguinte, seriam Simch e Vargas os dois alunos mais proeminentes da formatura da turma. ${ }^{16} \mathrm{~A}$ essa altura, Simch já agregava seus conhecimentos mineralógicos aos econômicos para pensar o progresso regional, como se percebe em seu artigo "Aspecto da questão econômica no Rio Grande do Sul", de 1907, no qual afirma a necessidade de se investir na extração de carvão de pedra para prover energia à indústria do estado, diminuindo as importações, e quiçá promovendo as exportações. Isso favoreceria as contas públicas e o progresso econômico, mas também evitaria a extração desmatadora da lenha. ${ }^{17}$

A extração do carvão em solo nacional era de grande importância nas primeiras décadas do século XX, pois o mineral era insumo industrial indispensável (Pesavento, 1985, p. 61). Simch se envolveria profundamente com esse tema científico-prático, elaborando estudos oficiais, artigos e discursos, coordenando visitas de alunos de ginásios e da Escola Superior

12 AF, 16 fev. 1893; AF, 9 jan. 1894, p. 3; AF, 19 jan. 1895, p. 6.

13 AF, 28 fev. 1900, p. 2; AF, 11 abr. 1901, p. 2.

14 AF, 20 nov. 1903, p. 2.

15 AF, 5 dez. 1906, p. 4; e AF, 6 dez. 1906, p. 2.

16 AF, 3 jun. 1907, p. 2; AF, 13 jul. 1907, p. 2; e principalmente AF, 26 dez. 1907, p. 2.

17 AF, 6, 7 e 8 mar. 1907, p. 1, p. 1 e p. 3, respectivamente. 
de Comércio às minas próximas a Porto Alegre, gerenciando as atividades nessas minas e disseminando seu conhecimento e experiência sobre o assunto. ${ }^{18}$ Todas essas ações serão efetuadas por Simch entre 1907 e 1935, em diversos cargos, vários deles exercidos concomitantemente: diretor do Museu Júlio de Castilhos, professor da Faculdade de Direito, professor e diretor de ginásios, diretor do Serviço Mineralógico e Geológico do estado (alçado em 1932 a Secretário Estadual das Obras Públicas). Ao longo desses anos, é constante a sua visão nacionalista em defesa do uso do carvão brasileiro. ${ }^{19}$ Em 1928, o então presidente do estado Getúlio Vargas visitaria, na companhia de Simch, "engenheiro fiscal" das minas, as jazidas de carvão de São Jerônimo. ${ }^{20}$

De 1907 em diante, Simch continuaria a trilhar a senda que se iniciara ao cursar a cadeira de economia política: foi um dos fundadores da Escola Superior de Comércio em 1909, ${ }^{21}$ e lançou seu livro Programma de Economia Social (1912), no qual vinham condensadas as lições ministradas nessa escola e na Faculdade de Direito. ${ }^{22}$ Em 1914, Simch foi um dos principais articuladores da fundação - nas salas da Faculdade de Direito - do "Instituto de Estudos Econômicos" (IEE) e seu primeiro presidente. ${ }^{23}$ No mês seguinte à fundação, ocorreu uma reunião do instituto, e Simch discursou, expondo argumentos contrários à intervenção pública na fixação das horas de trabalho e do salário. Tal argumentação apresentava um tom positivista, uma visão de não conflito entre as classes sociais, e ia, de forma geral, ao encontro do interesse empresarial. Essas ideias seriam mantidas e desenvolvidas por Simch nos anos seguintes (Pesavento, 1988, pp. 148 e 204-209).

Enquanto diretor do Serviço de Mineralogia e Geologia do Estado, Simch publicou um manual de mineralogia destinado às escolas brasileiras, baseado essencialmente em conhecimentos teóricos de autores europeus e em seus conhecimentos práticos do solo do Rio Grande do Sul (Simch, 1923). Ao longo dos anos de 1920, Simch ampliaria ainda mais sua projeção como figura pública, tornando-se diretor do Instituto Histórico

18 AF, 11 maio 1908, p. 2; AF, 25 jul. 1910, p. 4; e AF, 6 set. 1910, p. 1.

19 AF, 2 de jan. 1926, p. 1. (Texto de Simch: "Problemas econômicos e industriaes".)

20 AF, 14 maio 1928, p. 4; AF 17 maio 1928, p. 4; AF, 10 ago. 1928, p. 4.

21 AF, 16 dez. 1913, p. 3.

22 AF, 15 jan. 1912, p. 4.

23 AF 7 abr. 1914, p. 4. 
Geográfico do Rio Grande do Sul (IHG-RGS) e, consequentemente, do Arquivo Público estadual e, ainda, o primeiro presidente da Associação dos Funcionários Públicos do Estado. Diversas vezes, Simch foi chamado a discutir temas de relevância como, por exemplo, o fornecimento de energia para Porto Alegre e a fundação de um "Banco de Crédito Rural" no RS. ${ }^{24}$ No ano de 1929, a edição de 1912 do Programma de Economia Social se encontrava esgotada ${ }^{25}$ de modo que as duas edições seguintes, de 1931 e 1934, parecem justificadas não só pelos acréscimos de conteúdo que Simch viria a fazer, mas também pela necessidade de reimprimir a obra oficialmente utilizada nas aulas da Faculdade e já significativamente difundida.

Em 1931, com o Brasil sob o regime varguista e sofrendo os impactos da depressão internacional, Simch participou de reunião convocada pelo interventor Flores da Cunha para pensar-se o "reerguimento econômico do país", sendo designado vice-presidente da "comissão de propaganda para o reerguimento da economia nacional", a qual visava incentivar o consumo dos artigos de produção nacional, limitando o uso de artigos supérfluos, e sugerir aos poderes públicos as medidas para estimular, por todo e qualquer meio, a produção nacional. ${ }^{26}$ Mesmo em meio às turbulências econômicas, em 1931 formou-se uma comissão para já pensar em organizar as comemorações do centenário da "Republica Riograndense", no IHGRS, e Simch é nomeado presidente. ${ }^{27}$

No mesmo ano, Simch tornou-se diretor do porto da capital gaúcha e conclamou, em discurso, os poderes públicos e as empresas privadas a trabalharem em conjunto para a prosperidade do porto e da região. Deveria ser seguido o exemplo europeu de modernização do sistema comercial-econômico com eficiência, o que implicava uma centralização de tarefas contudo não seria desejável chegar-se à constituição de monopólios. Com a ajuda dos poderes públicos, uma companhia que fosse eficiente poderia "vir a ser a cellula matriz de uma grande empresa de cabotagem com capitaes rio-grandenses e com sede em nosso Estado". ${ }^{28}$

Em 1932, Simch assumiu a Secretaria das Obras Públicas do Estado, tratando, a partir daí, de muitos assuntos concernentes ao mercado e ao desen-

24 AF, 15 dez. 1924, p. 5; AF, 10 dez. 1927, p. 4.

25 AF, 1 jan. 1929, p. 38.

26 AF, 9 mar. 1931, p. 3.

27 AF, 1 jul. 1931, p. 4.

28 AF, 16 out. 1931, p. 2. 
volvimento econômico regionais e tendo de tomar decisões, por exemplo, a respeito da implantação da primeira packing house por determinação do poder público. ${ }^{29}$ Participou também de negociações com madeireiros sobre legislação e com produtores de vinho sobre a entrada de vinhos portugueses no estado. ${ }^{30}$ Em 1933, recebeu uma delegação alemã, interessada na construção de um porto no município costeiro de Torres. ${ }^{31}$ Em 1935, Simch deixaria a Secretaria de Obras ao ser nomeado desembargador, e com esse cargo aposentou-se um ano depois. ${ }^{32}$ Em 15 de outubro de 1937, em decorrência de um acidente de carro, Francisco Simch faleceu em Porto Alegre.

\section{Programa de economia social: integrando teoria e política econômica}

\subsection{Preâmbulos e "economia pura"}

A principal obra de Francisco Simch no campo específico da economia foi elaborada a partir de apropriações da tradição germânica de pensamento econômico. Para se ter uma ideia, na bibliografia da última edição de 1934, Simch arrolou 17 livros alemães de um total de 46, prevalecendo uma clara influência "continental" sobre a anglo-saxã (Simch, 1934, pp. 488-489). Além dos livros em alemão, a divisão linguística das referências listadas era a seguinte: oito em francês, sete em italiano, oito em espanhol, quatro em inglês e dois em português (de autoria de brasileiros, a saber: Almeida Nogueira e Clóvis Bevilaqua). Não é o caso de citar cada autor referido, mesmo porque vários deles aparecem na bibliografia, mas não são abordados no decorrer do texto. Vale, contudo, fazer algumas observações sobre os critérios que possivelmente orientaram a elaboração dessa lista bibliográfica que, por estar incluída num manual, tinha caráter de guia de leitura.

Entre os franceses, aparecem dois livros do economista e geógrafo Leroy-Beaulieu e um de Paul Cauwès, este considerado um dos principais simpatizantes da escola histórica alemã na França (Poitier, 2016). No grupo

29 AF, 24 jul. 1933, p. 4.

30 AF, 3 maio 1932, p. 2.

31 AF, 29 abr. 1933, p. 4; AF, 8 maio 1933, p. 8.

32 AF, 5 jul. 1935, p. 3. Há uma nota elogiosa no jornal, em referência ao "tratado" de economia de Simch, que influenciou "mais de uma geração de universitários". 
dos ingleses, para além de Marshall, citado na epígrafe, figuravam Henry D. MacLeod, Joseph Shield Nicholson, e Henry Sidgwick. É conhecida a influência de MacLeod, ligado à noção de valor-utilidade e aos princípios da banking school, na Faculdade de Direito de São Paulo (Hutchison, 1972, p. 451; Gremaud Jr., 1997, pp. 46-56). Nicholson, por sua vez, formou-se em direito em Heidelberg e foi influenciado pelo historicismo tanto alemão quanto britânico (Groenewegen, 2010, p. 5 e p. 9). Chama a atenção, de resto, a ausência, nesse guia de leitura, de economistas clássicos, britânicos ou continentais, como Smith, Ricardo, Stuart Mill e Say.

Para além dessa seletividade bibliográfica, a forma e o conteúdo do manual tiveram inspiração germânica. Do ponto de vista da forma, a apresentação de um livro inicial de "economia pura", seguido de um de "política econômica" correspondia, ainda que de forma incompleta, à divisão tripartite habitual nos manuais alemães desde Karl Heinrich Rau. Simch não produziu, contudo, um manual de finanças públicas, disciplina que ministrava com alguma irregularidade (Sá, 1981, pp. 44-46). No plano do conteúdo, a seleção de tópicos e o tratamento mais descritivo do que teórico das matérias também refletiam os manuais alemães de finais do século XIX e início do XX. A partir de meados do século XIX, com as contribuições inaugurais de Wilhelm Roscher, ganhou força na Alemanha o historicismo em economia, que se associou a um projeto nacionalista e protecionista a partir dos anos de 1870, sob a liderança de Gustav Schmoller. Essa ascensão de uma escola histórica não significou, contudo, um completo isolamento com relação aos desenvolvimentos teóricos ocorridos em outros contextos.

De acordo com Streissler (2001), é possível identificar na Alemanha oitocentista uma tradição "protoneoclássica", representada por Karl H. Rau, Friedrich B. W. Hermann e Wilhelm Roscher. Esses economistas eram adeptos do valor subjetivo, isto é, recusavam o trabalho como medida absoluta, e enfatizavam a satisfação de necessidades individuais como referência para o valor. Esse tratamento, entretanto, não deve ser confundido com a formalização matemática da economia presente em marginalistas como Jevons e Walras: afinal, esse trio de pensadores alemães produziu manuais descritivos, direcionados à formação de burocratas e homens de negócio. Era essa preocupação ligada aos problemas concretos, à relativização dos princípios teóricos mais gerais por meio de certa "empiria", que articulava a influência historicista à crítica da teoria clássica do valor, 
baseada no trabalho como medida universal. $O$ procedimento de relativizar os princípios teóricos expostos perpassa todo o livro de Simch, que se apropriou não exatamente de uma linhagem específica de pensamento econômico alemão, mas dessa articulação entre historicismo, relativismo teórico e pendor pedagógico que deu o tom de boa parte da produção alemã em economia no século XIX.

O Programa, cuja finalidade era didática, deve ser entendido como um texto em processo de elaboração ao longo de algumas décadas. A primeira edição, de 1912, foi um opúsculo que incluía apenas uma divisão entre "Parte geral", na qual estavam algumas definições básicas, e a "Parte especial", em que eram desenvolvidos os "grandes temas" produção, consumo, circulação e distribuição. A cada tema foi atribuído um "livro". O mais extenso era o Livro III, sobre circulação, por incluir capítulos sobre "transportes", "comunicações", "pesos e medidas", "bancos", nos quais, para além da exposição sintética de alguns princípios teóricos, descreviam-se em detalhes as modalidades de existência de cada um desses aspectos da realidade econômica. No capítulo sobre comunicações, por exemplo, mencionava-se brevemente a importância dos sistemas de comunicação para a circulação econômica e, em seguida, fazia-se uma descrição do evolver histórico da comunicação humana, apontando as conveniências e inconveniências de cada meio. A descrição culminava com o telégrafo e a tecnologia de ponta à época: o telefone (Simch, 1912, pp. 171-176).

A reedição de 1931 resultou numa versão expandida, devido à inclusão de uma nova parte, sobre política econômica. $\bigcirc$ volume foi dividido em duas grandes seções: o livro de 1912 tornou-se "economia pura" e o restante saiu sob o título de "política econômica". No prefácio a essa nova edição, Simch explicou que o acréscimo da parte referente à política econômica seguia a "lição do Prof. van der Borght de cujas doutrinas muitos e extensos traços se encontram neste trabalho" (Simch, 1931, p. 1). Com efeito, Borght publicara, em 1903, na Alemanha, um pequeno livro sobre a Volkswirtschaftspolitik, a cuja reimpressão (de 1905) Simch decerto teve acesso. Em 1934, o Programa de economia social ganhou sua terceira e última edição, pouco modificada com relação à segunda. $O$ único acréscimo significativo se deu ao final: capítulos sobre o "ritmo" da economia social, sobre a economia dirigida e sobre a história da política econômica.

No prefácio de 1912, Simch procurou estabelecer uma diferenciação entre "o modo de ser e de explicar os fenômenos" e "o modo de melhorá-los 
e torná-los mais proveitosos" (Simch, 1912, pp. III-IV). Seguindo essa divisão, Simch separou a fenomenalidade econômica, que seria objeto do volume publicado em 1912, das normas de política econômica, que abordaria mais tarde, na segunda edição (1931). Sintomaticamente, Simch retiraria esse prefácio da segunda edição, substituindo-o por outro, mais curto. A partir da inclusão da parte relativa à política econômica, Simch parece ter adotado uma postura diferente, aderindo à proposição de Richard van der Borght de que a separação entre política econômica e "economia pura" era de natureza apenas didática.

Nos parágrafos dedicados ao método, já na edição de 1931, Simch enfatizava que "os estudos economicos são energicamente caracterisados pelo seu traço eminentemente social" e sempre que a doutrina esquece isso, seu trabalho é "defeituoso". Recusava claramente qualquer "exame de condições a Robinson Crusoe", exigindo que esse tipo de prática nas ciências sociais fosse fulminado. A ciência deveria integrar os fenômenos econômicos ao meio e à sociedade em que se passam. Simch advertia, todavia, para que não se confundisse, no âmbito da fenomenalidade econômica, a política econômica e a ciência da administração. Ao fim e ao cabo, optava pelo procedimento indutivo. A necessidade imposta ao economista seria perscrutar "o modo pelo qual um phenomeno se mostra aqui ou ali ou alhures", despi-lo e descarná-lo daquilo que lhe é acessório, examinar suas constantes e elementos variáveis para enfim elaborar um "conceito geral". As duas modalidades não eram excludentes, permitindo "verificações interessantíssimas" da indução sobre a dedução (Simch, 1931, pp. 31-32).

No Livro Segundo, sobre o consumo, na parte referente ao "consumo de classes", Simch fez referência direta a Ernst Engel (1821-1896), por meio da lei que leva o nome desse estatístico e, em certo sentido, economista. $O$ objetivo dessa parte do texto era relacionar o consumo com os perfis das várias camadas populacionais: cada classe social teria seu modo particular de consumo (Simch, 1931, pp. 108-109). A lei de Engel, exposta por Simch de maneira sucinta, descreve a relação inversa que se estabelece entre a renda das famílias e o consumo de certos bens: "O economista allemão Engel no estudo do assumpto conseguiu formular uma lei que tem seu nome e assim enunciada: quanto mais pobre uma familia tanta maior porção de seu rendimento gasta com a alimentação" (Simch, 1931, p. 108).

A apropriação dessas ideias tinha importância não apenas teórica, mas servia como validação da defesa do método indutivo em economia. Ernst 
Engel constatara, a partir de dados compilados para a década de 1850 pelo estatístico belga Édouard Ducpétiaux (1804-1868), que os gastos dos trabalhadores com alimentação tendiam a declinar como proporção da renda à medida que esta aumentava. A partir do trabalho de Engel como chefe do Escritório Real de Estatística da Saxônia, coletando e examinando dados de consumo das famílias, a tese foi confirmada por mais uma verificação empírica e ganhou contornos de "lei econômica". A "lei de Engel" é tida pela historiografia do pensamento econômico como exemplo de caso bem-sucedido do uso do método indutivo, pois dados estatísticos levaram, quase diretamente, a conclusões de natureza teórica (Grimmer-Solem, 2011, pp. 528-529; Erreygers, 2009).

Ainda no campo da "economia pura", as reflexões de Simch sobre o salário refletiam visões oitocentistas convencionais. Simch definia o salário como "a renda percebida por aquelles que locam a sua actividade a uma pessoa ou empreza qualquer" (Simch, 1931, p. 236). Em seguida, explicava que seria natural os operários buscarem as empresas que paguem os melhores salários, ao passo que as últimas preferiam os trabalhadores que exigissem menor pagamento. Cada uma dessas tendências seria "perfeitamente justa, perfeitamente explicável" e, nesse sentido, seria um descuido falar em luta entre o trabalho e o capital. O fenômeno se deveria a uma diversidade de pontos de vista entre operários e patrões, não podendo haver conflito "no sentido vulgar do termo", entre dois elementos essenciais da produção.

Embora fizesse essa ressalva quanto ao conflito capital versus trabalho, Simch apropriou-se de elementos da teoria marxiana dos salários, ao apontar para a especificidade do trabalho com relação a outras mercadorias negociadas na economia. Vendedores de produtos convencionais, argumentava Simch, teriam alguma margem de manobra: numa situação de baixa de preços, podiam retirar-se do mercado a fim de aguardar momento mais propício para desovar sua mercadoria. Essa retirada causaria um recuo da oferta e os preços tenderiam a inverter a tendência de queda. $O$ mesmo não se aplicava ao trabalho: nesse caso, haveria, ao contrário, uma elevação na oferta de trabalho como consequência da diminuição dos salários (Simch, 1931, p. 237). Simch advertia, no entanto, que a teoria de Marx pecava ao imaginar a classe operária como todo homogêneo sob o ponto de vista do salário, fazendo, assim, uma generalização descabida (Simch, 1931, p. 241). 


\subsection{Política econômica: assimilação e adaptação}

Após a exposição de tópicos referentes à "economia pura", abarcando temas como consumo e salários, Simch passou à discussão da "política econômica", que ocupa a metade final de seu livro. O acréscimo dessa parte à obra, nas edições de 1931 e 1934, conferiu ao manual de Simch algo de específico, com relação aos livros-texto de economia política produzidos no Brasil para cursos de direito. Já no início da obra, Simch buscara filiar essa parte final às "lições do prof. van der Borght". O perfil de economista representado por Borght, bem como os conteúdos abordados em seu livro, fazem de sua assimilação um procedimento funcional para Simch. Richard van der Borght foi um economista eminentemente prático, voltado para reflexões sobre o funcionamento concreto de instituições e processos econômicos, tendo-se notabilizado, na Alemanha, por sua atuação nas câmaras de comércio de Aachen e de Colônia. Ademais, Borght acreditava numa divisão apenas didática entre teoria e política econômica, não havendo separação "essencial" entre esses campos do saber. A trajetória biográfica e intelectual de Borght pode ajudar a compreender melhor essa apropriação de Simch.

Nascido em Potsdam, em 1861, Richard van der Borght iniciou seus estudos acadêmicos em 1880, na Universidade de Halle. Começando a formação acadêmica na área de teologia, Borght em breve transferiu-se para economia política, tendo sido influenciado por professores Ludwig Elster (1856-1935) e Joseph Conrad (1839-1915). Anos mais tarde, Borght contribuiria com sete verbetes para o Dicionário das Ciências do Estado, ${ }^{33}$ organizado por Elster, Conrad e outros. Esse léxico, reeditado diversas vezes, tornou-se obra de referência importante na Alemanha, reunindo verbetes sobre temas econômicos redigidos, entre outros, por Gustav Schmoller e Adolph Wagner.

Em 1883, Borght doutorou-se em Halle com tese sobre as sociedades por ações: um tema da ordem do dia, tendo em vista as instabilidades acarretadas pelo Gründerkrach (ou "choque da fundação"), como ficaria conhecido o pânico financeiro de 1873, que se seguiu ao otimismo dos anos de fundação do Reich. Uma legislação pró-laissez faire fomentara a criação

$33 \bigcirc$ Handwörterbuch der Staatswissenschaften trazia verbetes com definições de termos econômicos e ligados ao universo do que hoje se conhece como ciências sociais. A primeira edição foi publicada em Jena, em vários volumes, entre 1890 e 1897. 
de empresas e de supercapacidade na economia alemã nos anos iniciais da década de 1870. Devido à crise econômica dos anos de 1870 e a abusos no sistema prussiano de concessão de ferrovias, a lei de ações seria alterada em 1884. O contexto era, portanto, propício à publicação de uma tese sobre a organização das sociedades por ações (Henning, 1994, pp. 24-25),

Em 1884, assumiu o cargo de Secretário da Câmara de Comércio de Aachen. Para além dos temas relativos às atividades comerciais, estiveram presentes em sua produção assuntos como a política colonial alemã, o projeto de canalização do rio Mosel, a lei de proteção às marcas e a influência do comércio intermediário no desenvolvimento dos preços. Suas monografias foram complementadas por artigos publicados em periódicos de renome, como Finanz-Archiv e Schmollers Jahrbuch. Esse reconhecimento intelectual foi expresso, também, na confiança de professores como Conrad, Elster e também Schmoller, que recomendaram Borght, em 1890. para um posto mais prestigiado do que o anterior: Secretário da Câmara de Comércio de Colônia. Embora em menor ritmo, Borght continuou produzindo textos acadêmicos, tendo publicado duas monografias sobre a temática dos transportes - fluviais e ferroviários - na região da bacia renana (Henning, 1994, pp. 27-33).

Da virada do século até sua aposentadoria, em 1912, Borght atuou em Berlim, para onde se transferiu em 1900, a fim de trabalhar no Ministério do Interior, no qual lidou com as articulações entre a regulação de monopólios e a legislação trabalhista. Essas questões, vale lembrar, eram urgentes numa economia alemã cada vez mais cartelizada (Henning, 1994, pp. 36-37). Até início dos anos de 1910, sua atividade intelectual continuou, por meio de publicações científicas de caráter didático. Exemplos disso foram um livro sobre princípios de política social (1904) e o opúsculo Volkswirtschaftspolitik, cuja edição original foi de 1903 e que chegou, em sua reimpressão de 1905, às mãos de Francisco Simch, em Porto Alegre. O livro foi reeditado sucessivas vezes: sua quarta e última versão, expandida e atualizada, data de 1927. Embora Borght seja raramente mencionado em compêndios de história das ideias econômicas, mesmo naqueles voltados para as linhagens germânicas de pensamento, a disseminação internacional de sua obra parece não ter sido desprezível. Para além da assimilação por Simch no Brasil, foi possível identificar traduções castelhanas de seus manuais de política econômica e de finanças públicas, que teriam sido efetivamente assimilados na Espanha (Astigarraga; Zabalza, 2016, p. 111; Borght, 1932). 
A definição do escopo da política econômica e de sua posição com relação à economia teórica, bem como a escolha e ordenamento das matérias a serem tratadas, evidenciam as afinidades entre os "economistas práticos" Richard van der Borght e Francisco Simch. Este último definiu a política econômica como as medidas postas em ação pelo Estado no campo da economia. O Estado, por sua vez, seria, para Simch, "um instituto evolutivo, originario das sociedades humanas, e destinado a conduzil-as" (Simch, 1931, pp. 271-272). O Estado não deveria ser, contudo, "elemento causal" em economia, devendo, tão somente, amparar certos fenômenos econômicos que, por qualquer circunstância, encontrem óbices a seu pleno funcionamento. A ação econômica do Estado, portanto, derivava legitimidade de sua função "cultural" ou "civilizacional": o Estado deveria "guiar e conduzir os povos". Dessa forma, a finalidade do Estado - e das normas de política econômica - "é e tem sempre de ser" o interesse coletivo, o bem-estar social (Simch, 1931, p. 273).

Nesse sentido, Simch fez uma breve recapitulação histórica da atuação do Estado, numa visão relativamente "progressista" que justificava o papel amplo do Estado diante das complexidades da vida moderna. Se, com a queda do feudalismo, o regime do absolutismo monárquico representou um progresso face ao "desmembramento feudal", logo apareceu a tendência liberal do ne pas trop gouverner, que desafogou a economia de "privilégios e garantias" de outrora. O Estado moderno devia, portanto, fazer jus ao "gráo de desenvolvimento a que a humanidade chegou". Para garantir o bem-estar social, o Estado teria que tomar para si certas tarefas (Simch, 1931, p. 275).

O bem-estar, no entanto, era um conceito relativo, variável no tempo e no espaço. Simch alertava para as "doutrinas e correntes filosóficas" que pretendem dominar e orientar, com regras invariáveis no tempo e no espaço, as aglomerações humanas "tão variáveis, instáveis na sucessão dos tempos e logares" (Simch, 1931, p. 276). À maneira do positivismo comtiano, questionava também a divisão tripartite dos poderes, afirmando que, apesar do atual "fetichismo do conceito", essa partição não seria essencial à boa marcha do Estado. Em suma, Simch via a política econômica como as medidas tomadas por um Estado que deveria refletir as condições históricas de sua época, em perspectiva que se poderia chamar de relativista. $\mathrm{Na}$ atualidade, Simch dizia, o poder público deveria assumir para si diversas funções de modo a proporcionar o bem-estar da população. $O$ bom 
desempenho de tais funções seria o principal, senão o único, critério a justificar e orientar a ação estatal (Simch, 1931, p. 277).

O parágrafo de Simch descrito acima, "\$.1. Estado, suas funcções. Politica Economica", pode ser visto como uma reprodução adaptada da primeira seção do livro de Borght, intitulada "Conceito e tarefas da política econômica". Tanto a definição da política econômica como "conjunto das medidas a serem tomadas pelo Estado", quanto seu caráter relativo, haviam sido assinalados por Borght, que fora ainda mais enfático que Simch. Afirmara que "em nenhum outro lugar o perigo da generalização é tão grande quanto no âmbito da política econômica" (Borght, 1905, p. 9). Isso levaria, segundo Borght, a uma necessária e contínua verificação das conclusões por meio dos fatos presentes e passados, aferidos pela estatística e pela história econômica. Merece destaque, ainda nessa parte introdutória, a supressão, por parte de Simch, do prefácio publicado em 1912, que de alguma maneira enfatizava a separação entre economia pura e política econômica. Essa omissão parece estar em consonância com a postura de Borght, que considerava impossível uma separação rigorosa entre a "economia prática", como por vezes chamava a política econômica, e a economia "teórica". Esses indícios apontam para uma busca, por parte de Simch, de um referencial que o auxiliasse na formulação de uma proposta de ensino de economia que integrasse teoria e prática, ciência econômica e política econômica.

Feitas essas definições iniciais, Simch arrolou e analisou uma extensa série de medidas que considerava "de política econômica", divididas por área. Vale ressaltar que o escopo dessa política econômica era bastante amplo, indo do aproveitamento geológico do território à gestão monetária, passando pelos transportes e pelo abastecimento alimentar. No âmbito dessa gama de assuntos, destacam-se aqui dois: política de comércio externo e política de preços. $O$ caso do comércio externo evidencia que Simch aderiu à interpretação que Borght fazia da doutrina de Friedrich List. Em relação à defesa feita pelos industrialistas brasileiros no início do século $\mathrm{XX}$, que viam em List argumentos para a legitimação de tarifas aduaneiras, a visão apresentada por Simch era bastante moderada. Já a seção sobre a regulação dos preços é um exemplo interessante de apropriação de ideias estrangeiras que não se limita à reprodução do discurso assimilado.

No tocante ao comércio externo, Simch fez, primeiramente, uma descrição das medidas de política econômica à disposição dos Estados, 
traduzindo, quase palavra por palavra, os parágrafos de Borght referentes à Handelspolitik (política comercial). Simch introduziu uma separação entre as matérias que Borght não fizera. A seção Handelspolitk abarcava em Borght tanto medidas relativas ao comércio interno quanto ao internacional. Simch, por sua vez, fez um capítulo intitulado "Circulação" e dividiu-o nas seções: "Medidas referentes ao commercio interno" e "Medidas referentes ao commercio externo". O conteúdo seguia de perto o texto de Borght, embora um esforço de adaptação, por parte de Simch, seja perceptível. Diversos trechos foram traduzidos em toda sua extensão, mas exemplificações muito específicas relativas à Alemanha foram omitidas ou substituídas. Na seção sobre comércio interno, Simch omitiu um trecho de Borght sobre seguridade social dos trabalhadores comerciais. Já as linhas referentes à educação profissionalizante na Alemanha foram substituídas pela observação de que as escolas de comércio têm surgido "mais ou menos por toda parte, inclusivamente no Brasil". A essa constatação seguia-se a crítica de Simch: muitas das academias comerciais brasileiras eram dirigidas por indivíduos "de qualidades technicas duvidosas" e as instituições federais voltadas para esse fim padeciam de "vicio fundamental de organisação" (Simch, 1931, p. 391). Vale lembrar que a Escola de Comércio de Porto Alegre, que Simch ajudara a fundar em 1909 era, a essa altura, uma instituição estadual sul-rio-grandense.

O ponto de partida da seção sobre o comércio externo era, em Simch, o mercantilismo, sistema em que impostos de entrada, saída e trânsito de mercadorias eram utilizados com vistas a atingir o "máximo de vantagem" para os Estados nacionais. O Estado moderno, no entanto, teria abandonado os impostos de saída e de trânsito, mantendo os de entrada, que teriam papel importante para impedir a entrada excessiva de mercadorias estrangeiras. Aliados a esses impostos haveria, conforme Simch, objetivos estratégicos do ponto de vista do erário público: nas situações em que a intenção arrecadatória se sobrepujasse à salvaguarda da indústria local, os impostos poderiam ser chamados de "fiscais". Aqui, Simch foi bem mais sintético do que Borght, omitindo o detalhamento de algumas formas de tarifa comercial, para passar à comparação entre os "sistemas" protecionista e livre-cambista (Simch, 1931, p. 393).

Em seguida, Simch analisou, sempre seguindo as opiniões de Borght, as possíveis vantagens da aplicação de um e de outro sistema, adotando uma postura pragmática e relativista. Segundo Simch (e Borght), nenhum dos 
dois sistemas podia ser aplicado incondicionalmente. Todos os grandes Estados, incluindo a Inglaterra, alteravam as normas atinentes à política comercial conforme as circunstâncias das diferentes épocas. Não haveria - e nem era esperado que houvesse - uma sincronia entre os países na adoção dessa ou daquela política: cada país deveria buscar as medidas que mais lhe conviessem. Assim, o que se tinha era a coexistência de sistemas protecionistas e de livre-câmbio: "não pode haver doutrina uniforme nessa matéria" (Simch, 1931, p. 394; Borght, 1905, p. 111).

Essa visão relativista da política econômica era reforçada na leitura feita por Borght - e endossada por Francisco Simch - das ideias de Friedrich List (Borght, 1905, p. 111). No momento em que era necessário remover as antigas restrições "mercantilistas" às atividades econômicas, vicejaram as ideias de Adam Smith. Já na ocasião em que cada economia singular se via forçada a escolher entre "atrazar-se dos outros seguindo-os claudicante" ou ousar conquistar igualdade de condições, List desenvolveu sua teoria. Tendo relativizado as duas posições acerca do comércio externo, Simch afirmou que dessa forma estava explicada a unilateralidade tanto da proposta livre-cambista quanto da listiana. Do ponto de vista prático, afirmou que a perspectiva de List, segundo a qual somente a maquinofatura devia ser protegida, já estava abandonada desde que começara o surto agrícola dos países de cultura extensiva, cujos cultivos eram também objeto de políticas de proteção (a exemplo do Brasil, com o café). No entanto, Simch afirmava em consonância com Borght, a doutrina listiana da validade relativa de todos os sistemas político-econômicos "é hoje do domínio commum e somente em circulos muito restritos se acredita no valor absoluto da escola de livre cambio de Adão Smith" (Simch, 1931, p. 394; Borght, 1905, p. 111).

Para além da evidente mediação dos escritos de Borght, essa apropriação "equilibrada" das ideias de List - e ao mesmo tempo próxima daquilo que esse economista enfatizou no Sistema nacional de economia política - pode estar relacionada com um contato direto com a versão original do texto listiano. Um indício em favor desse contato com a obra de List é a presença, no acervo da Faculdade de Direito de Porto Alegre, de uma edição de 1904 de Das nationale System der politischen Ökonomie, com assinatura de Simch e data de $1910 .{ }^{34}$ A assimilação de Simch parece, de resto, sintonizada com o 
projeto mais geral de List, e não apenas com a defesa de tarifas aduaneiras em particular, feita por industrialistas brasileiros da época, como Serzedelo Correia e Vieira Souto. Vale lembrar que List não preconizava a adoção de protecionismo aduaneiro por países tropicais, que deveriam, em sua visão, permanecer agrícolas. A utilização de seu nome como argumento de autoridade para legitimar tarifas comerciais no Brasil era expressão de uma leitura seletiva, e reflete mais os anseios de grupos locais do que a efetiva utilização do arcabouço listiano de pensamento sobre a economia (Fonseca, 2000; Boianovsky, 2013).

No tocante à política de preços, Simch seguiu Borght na defesa da liberdade de fixação de preços. Ambos reconheciam que a política econômica das cidades medievais, bem como do início da era moderna, nos séculos XVII e XVIII, tivera boas razões para intervir de forma bastante direta na formação dos preços, pois era necessário proteger os consumidores da carestia e os produtores da pressão concorrencial excessiva. Contudo, tais pressupostos não existiam mais no mundo moderno, tornando-se obsoleto esse tipo de ação econômica estatal direta (Simch, 1931, pp. 400-401). A intervenção mediata ou indireta, entretanto, subsistia, conforme o exemplo oriundo do contexto alemão descrito por Borght, e reproduzido por Simch.

No caso dos preços das padarias e das casas de pasto, exigia-se dos proprietários fixar listas de preço carimbadas pelas autoridades: tais valores não poderiam ser majorados sem a fixação de outra lista autorizada pelo respectivo órgão competente. Nesse caso, o preço não era fixado pelo poder público, mas os reajustes eram feitos com sua anuência. Em todos os outros casos, a formação de preços deveria fazer-se, na tradução de Simch "sem a intromissão do Estado" (Simch, 1931, p. 401; BORGHT, 1905, p. 123). Enfatizava-se a necessidade de o Estado ter cautela com relação à aferição e divulgação dos preços na economia. Aqui, Borght deu um exemplo de regulação do mercado, não traduzido por Simch, referente à lei alemã que estabelecia a necessidade de se precificar o gado de corte a partir do peso de abate. Haveria, ainda, casos especiais em que a liberdade de formação de preços poderia e deveria ser suspensa, como as grandes catástrofes naturais, greves, artifícios ilícitos etc.

No caso de o Estado produzir ele próprio alguma mercadoria em regime de monopólio, deveria estar atento para precificar de maneira a encontrar solução razoável para a "financiação do proprio monopolio", sem que isso prejudicasse os consumidores e os próprios interesses fiscais do poder pú- 
blico. Em mercadorias produzidas pelo Estado em regime de concorrência, deveria ser respeitado o preço comum, caso contrário o poder público estaria praticando "injusta e iniqua concorrência" a seus próprios cidadãos. Nesses casos, o Estado poderia servir como agente moderador, intervindo com produção própria, se houvesse um "encarecimento malsão" (Simch, 1931, p. 402; Borght, 1905, p. 124). Era nesse tipo de situação que, conforme Simch, se inseria o caso dos preços do carvão durante a Primeira Guerra. Aqui, Simch interrompeu sua tradução de Borght para inserir reflexões relacionadas a experiências concretas de política econômica, das quais participara diretamente. Em seus relatórios como diretor do Serviço Geológico, Simch já retratara a exploração de carvão, mas de um ponto de vista mais técnico: no Programa, tratou da questão na perspectiva da política de regulação dos preços.

Nesse sentido, relatou que, durante a conflagração europeia, os preços do "carvão de pedra nacional de consumo puramente interno" subiram de $23 \$ 000$ a $73 \$ 000$ rapidamente. Isso criou entraves para as indústrias e os transportes, motivando a mensagem de 1917, do presidente do Rio Grande do Sul, Borges de Medeiros, transcrita por Simch. O texto assinalava que a intervenção na indústria de extração carbonífera era necessária e que o governo gaúcho optaria pela intervenção direta, por meio da exploração estatal do produto. Isso permitiria, conforme Borges de Medeiros, reduzir os lucros do empreendimento enquanto fosse necessário, para que fossem feitos os melhoramentos de que carecia o serviço. Também permitiria ao Estado atuar como regulador de preços, impedindo a "cobiça mercantil". Por fim, Medeiros apontou a importância do empreendimento estatal como garantia contra os monopólios e trustes, dos quais seria fácil tornar-se presa a "indústria carbonífera" (Simch, 1931, pp. 402-403).

Simch endossou toda essa argumentação do presidente do estado, asseverando que os preços baixaram consideravelmente assim que o estado "jogou ao consumo as primeiras tonneladas de sua producção". De 70\$000, o preço teria baixado, sempre de acordo com o relato, a 43\$000, com a oferta do carvão explorado pelo poder público. Na descrição apresentada, a exploração teria vigorado de 1917 até 1923, quando foi interrompida "a pretexto de revolução". Esse período, vale lembrar, coincide com a gestão de Simch à frente do Serviço Geológico e Mineralógico do Estado, sendo a pausa correspondente à Revolução de 1923. Simch, todavia, não entrou em pormenores sobre o movimento político de 1923, que opôs novamente 
ximangos a maragatos, expondo as fissuras da política sul-rio-grandense. Em 1926, a campanha seria retomada: "tenaz, segura, firme". Porém, em 1928, mudando o presidente do estado, na expressão de Simch, "foi tudo por água abaixo". As minas do governo do estado - visitadas pelo novo presidente estadual Getúlio Vargas, na companhia de Simch nesse mesmo ano - acabaram sendo entregues a um "trust carioca" e o carvão de pedra estaria subindo de preço (Simch, 1931, p. 403).

Esse procedimento de apropriar-se do texto de um autor alemão, traduzindo-o e fazendo-lhe acréscimos e modificações, repetiu-se no capítulo final da parte do Programa relativa à política econômica, adicionado ao livro na última edição, de 1934. Dessa vez, porém, a referência não foi o manual de Borght, mas, sim, outro livro-texto: Volkswirtschaftslehre, escrito por Hugo Schober (1820-1882), que fora, assim como Borght, um "economista prático", voltado para a área agrícola. O foco de sua atuação como professor e autor fora a agronomia, tendo publicado trabalhos sobre, por exemplo, o cultivo do tabaco e a teoria dos sistemas econômicos na agricultura. Foi professor da Academia de Agronomia e Silvicultura de Tharandt, na Saxônia. Sua obra mais abrangente, não concluída, foi um compêndio de quatro volumes intitulado Manual de agronomia para agrônomos e economistas do Estado, voltado para o público universitário. O manual de Volkswirtschaftslehre ou "economia teórica", do qual Simch se apropriou, foi publicado pela primeira vez em 1859 e era parte de uma série de Katechismen. "Catecismo" referia-se, nesse caso, a uma espécie de almanaque, isto é, um livro de divulgação de informações relativas a um campo específico do saber. A sexta edição, que chegou às mãos de Simch, foi preparada por Eduard Otto Schulze e publicada em 1905, seguindo a prática de se fazer edições, revistas e ampliadas de manuais, inclusive após a morte do primeiro autor (Schober; Schulze, 1905).

O último capítulo do livro-texto de Simch foi uma adaptação das seções finais do catecismo de Schober-Schulze. A primeira modificação já seria feita no título. O nome da seção de Schober era "A ciência da economia política em seu desenvolvimento histórico", já Simch deu o título de "História da política econômica", pois o capítulo deveria fechar a parte do livro referente à política econômica. Os acréscimos mais substantivos de Simch ao texto de Schober foram referentes ao campo da "economia dirigida". Antes de iniciar a "história da política econômica", Simch expôs algumas ideias sobre a economia planificada, ressaltando sua importância 
para combater o "estado anárquico" da economia de mercado, causado pelo fato de os indivíduos agirem em interesse próprio, sem levar em conta os objetivos maiores da coletividade (Simch, 1934, p. 456). Embora admitisse os problemas envolvidos na estruturação de uma economia dirigida, reconhecia que o caminho do planejamento se apresentava à humanidade de forma mais ou menos incontornável (Simch, 1934, p. 460).

$\mathrm{Na}$ recapitulação histórica das ideias econômicas, Simch seguiu de perto o manual de Schober-Schulze, sendo o ordenamento das matérias praticamente idêntico: "mercantilismo", "fisiocracia ou economismo", "industrialismo" (que incluía Smith, Ricardo e Malthus), "livre-câmbio e protecionismo" e "socialismo e comunismo". Simch acrescentou, ao final, uma seção intitulada "Bolchevismo. Os Soviets Russos", na qual descreveu alguns traços gerais da planificação soviética, em especial a concepção dos planos quinquenais. Nas seções "Livre-câmbio e protecionismo" e "Socialismo e comunismo", fez, em sua tradução, adaptações dignas de nota. Simch parece ter "amenizado" o tom nacionalista, adotado por economistas da segunda geração escola histórica alemã (e presente na reedição feita por Schulze da obra de Schober). Suprimiu, por exemplo, a adjetivação presente no original alemão para qualificar a doutrina de Friedrich List. Em duas oportunidades, List e sua obra foram qualificados como "geniais" no manual de Schober-Schulze, ao passo que Simch limitou-se a descrever, de forma menos entusiasmada, os traços gerais do pensamento listiano, ressaltando sua crítica à economia clássica e sua exigência de que se "educassem" as forças produtivas latentes no povo (Simch, 1934, pp. 469-471; Schober; Schulze, 1905, p. 499).

Na parte referente ao socialismo, Simch fez um resumo da exposição de Schober-Schulze, omitindo praticamente toda a revisão histórica da literatura socialista, que, bem de acordo com a tradição germânica, expunha definições de "socialismo" da Antiguidade clássica aos socialistas alemães. Num parágrafo sobre o socialismo "moderno ou científico", Simch fez uma intervenção reveladora de seu pendor para a conciliação de classes, de inspiração possivelmente positivista. Conforme Schober-Schulze, "o socialismo moderno é em sua essência um produto do desenvolvimento industrial da modernidade. Seu ponto de partida é o antagonismo entre trabalho e capital (...)" (Schober; Schulze, 1905, p. 503). Simch adjetivaria: "Seu ponto de partida é o pretenso antagonismo entre trabalho e capital" (Simch, 1934, p. 473, grifo nosso). 
Essas adaptações na tradução, bem como a seleção de temas a serem incluídos nesse bosquejo de história do pensamento econômico, apontam para um reconhecimento da importância do protecionismo de List e para uma defesa do planejamento como instrumento de política econômica indispensável. Porém, são indícios, também, de uma cautela com o nacionalismo econômico e, sobretudo, com o socialismo e com a teorização baseada na noção de luta de classes. A planificação deveria evitar a anarquia, funcionando com um sentido claro de conciliação de classes. Mais do que contraparte econômica de uma "ditadura do proletariado", o planejamento econômico seria uma ferramenta à disposição de um Executivo forte e "condutor" da sociedade como um todo, conforme prescrevia o positivismo. Após esses acréscimos ao Programa, na edição de 1934, Simch não publicou trabalhos que tenham chegado aos nossos dias.

\section{Considerações finais}

No processo de industrialização, urbanização e modernização do Brasil, surgiram forças políticas e intelectuais que fermentavam no ambiente dos novos tempos. Formada em moldes étnicos e culturais distintos daqueles de outros estados da nação, a sociedade sul-rio-grandense que se constituía ao se iniciar o século XX viria a percorrer uma trajetória singular. Assimilaria grandes levas de imigrantes, entre os quais alguns - principalmente os de origem germânica - ascenderam à elite regional. Elite que encontrou nas propostas positivistas um alicerce para comandar a sociedade com o império da força e com o poder discursivo da racionalidade e da cientificidade. Na virada do século, manifesta-se um processo de "autonomização" institucional-intelectual no estado: criam-se faculdades, museus, institutos, dentro dos quais a elite, que até então dependia das faculdades do Sudeste ou Nordeste, poderia ela mesma formar seus quadros e dinamizar a vida cultural e científica. A trajetória de Francisco Rodolfo Simch é ilustrativa desse momento, pois compõe-se não só da vivência e dos estudos na Escola de Minas de Ouro Preto, um centro de referência intelectual em que convergiam elites de várias regiões do país, como também dos estudos e da atuação profissional (docente, científica e prática) no contexto específico da dinamização da sociedade sul-rio-grandense. E, nesse sentido, seu esforço intelectual em buscar diversas fontes, com destaque para as germâ- 
nicas, pode ser visto como singular e mesmo inovador frente ao cenário do ensino e da produção de conhecimento em economia no Brasil.

As publicações de Simch e de seus contemporâneos apoiavam-se em formatos, abordagens, argumentos e conceitos provenientes de obras de autores europeus, porém, no conteúdo e em algumas perspectivas políticas e ideológicas, essa produção brasileira já demonstrava ser em parte preenchida por questões nacionais. Tomando as duas principais áreas do conhecimento em que Simch publicou obras científicas - mineralogia-geologia e economia -, poderíamos destacar, como exemplos dessa articulação entre conceitos estrangeiros e conteúdo nacional, a constituição mineral do solo do Rio Grande do Sul e a experiência da exploração de carvão nas minas do estado. Tanto o solo quanto o evento da exploração econômica afiguram-se como "conteúdo local" a ser desvendado por métodos e conceitos europeus. No manual de mineralogia, Simch lançou-se ao projeto de descrever, com o ferramental da ciência ocidental, o solo ou - por que não dizer - o "palco", sobre o qual a ação econômica poderia desenvolver-se. Como ramificação institucional desse projeto descritivo e expositivo, assomava o Museu Julio de Castilhos, fruto meridional da modernização cultural brasileira na belle époque. Já no plano da experiência econômica, a exploração das riquezas desse solo aparece, no Programa de economia social, inserida num quadro geral cujas linhas-mestras eram as teorias e experiências europeias, em especial as de origem alemã.

Destacam-se, nesse sentido, as ideias de Friedrich List, das quais Simch fez uma leitura mais voltada para o relativismo dos instrumentos de política econômica do que para a defesa incondicional de uma agenda de protecionismo aduaneiro, como era comum entre os industrialistas atuantes no Rio de Janeiro e em São Paulo. Isso pode estar relacionado a um contato mais direto com a obra desse pensador e à mediação do manual de política econômica de Richard van der Borght, conhecido na Alemanha de seu tempo como economista prático, ligado às reflexões práticas e atuante nas câmaras de comércio da Renânia. Para além de mediar a leitura de List, Borght serviu como referência para que Simch acrescentasse a seu Programa original uma parte relacionada à política econômica, na qual utilizou o procedimento histórico-descritivo para tratar de uma série de questões relacionadas à vida econômica.

Nessa parte de seu livro-texto, Simch proporcionou exemplos de apropriação criativa de ideias, na medida em que utilizou não só a Volkswirt- 
schaftspolitik de Borght, mas também o compêndio mais teórico de Schober-Schulze como eixos organizadores de sua exposição didática, fazendo traduções convenientes e intervindo no texto em vários momentos. Por exemplo, a questão da exploração carbonífera pelo governo gaúcho aparecia como um "caso", dentro do esquema de Borght, no qual a intervenção estatal na formação dos preços mostrava-se certeira, pois era preciso evitar o "encarecimento malsão". Mesclavam-se ideias provenientes de um livro-texto alemão sobre o papel do Estado no processo de precificação, com a descrição de uma experiência, concreta e local, de política econômica. Essa combinação - em certo sentido, original - reforça o discurso "importado", mas também o modifica, visto que se suprimem preocupações relativas ao universo germânico para dar destaque a questões que faziam muito mais sentido no polo "brasileiro-meridional" da disseminação internacional de ideias.

\section{Referências}

ASTIGARRAGA, Jesus; ZABALZA, Juan. The German Historical School in Spain: from the fringes to mainstream". In: CARDOSO, José Luís; PSALIDOPOULOS, Michalis (Ed.). The German Historical School and European Economic thought. London, New York: Routledge, 2016.

BOIANOVSKY, Mauro. Friedrich List and the Fate of Tropical Countries. History of Political Economy, v. 45, n. 4, 2013.

BORGHT, Richard van der. Política económica. Barcelona: Labor, 1932.

BORGHT, Richard van der. Volkswirtschaftspolitik. Leipzig: Göschen, 1905. (Exemplar da Faculdade de Direito da UFRGS, Seção de Obras Raras)

CARDOSO, José Luís. Reflexões periféricas sobre a difusão internacional. Nova Economia, 19 (2), 2009.

ERREYGERS, Guido. Economics in Belgium. In: DURLAUF, Steven N.; BLUME, Lawrence E. The New Palgrave Dictionary of Economics. Online Edition. Palgrave Macmillan, 2009.

FONSECA, Pedro Cezar Dutra. As origens e as vertentes formadoras do pensamento cepalino. Revista Brasileira de Economia, v. 54, n. 3, 2000.

FONSECA, Pedro Cezar Dutra. Vargas: o capitalismo em construção. São Paulo: Brasiliense, 1989.

GERTZ, René. O aviador e o carroceiro: política, etnia e religião no Rio Grande do Sul dos anos 1920. Porto Alegre: EDIPUCRS, 2002.

GREMAUD JR., Amaury. Das controvérsias teóricas à politica econômica. Tese (Doutorado) Faculdade de Economia, Administração e Contabilidade da Universidade de São Paulo, 
São Paulo, 1997

GRIMMER-SOLEM, Erik. Engel's Law. In: SOUTHERTON (Ed.). Encyclopedia of Consumer Culture. v. 3. Thousand Oaks, CA: SAGE Publications, 2011.

GROENEWEGEN, Peter. Joseph Shield Nicholson (1850-1927): An early student of Marshall at Cambridge, Later Quite Critical of Marshall and his Economics. In: $23^{\text {rd }}$ CONFERENCE OF THE HISTORY OF ECONOMIC THOUGHT SOCIETY OF AUSTRALIA, Sydney, 2010. (disponível on-line)

HAGEMANN, Harald; RÖSCH, Matthias. Economic Textbooks in the German Language Area. In: AUGELLO, Massimo M.; GUIDI, Marco E. L. (Ed.) The Economic Reader. London, New York: Routledge, 2012.

HENNING, Friedrich-Wilhelm. Richard van der Borght. In: Rheinisch-Westfälische Wirtschaftsbiographien. Band 15. Münster: Aschendorff, 1994.

HUTCHISON, T. W. The 'Marginal Revolution': Decline and Fall of English Political Economy. History of Political Economy, 4 (2), 1972.

LAGEMANN, Eugenio. Imigração e industrialização. In: DACANAL, José Hildebrando (Org.). RS: imigração e colonização. Porto Alegre: Mercado Aberto, 1980.

LIST, Friedrich. Das nationale System der politischen Ökonomie. Jena: Fischer, 1904. (Exemplar pertencente a Francisco Simch)

LOVE, Joseph. Rio Grande do Sul and Brazilian Regionalism. Stanford: Stanford University Press, 1971.

NETO, Lira. Getúlio: dos anos de formação à conquista do poder (1882-1930). São Paulo: Companhia das Letras, 2012.

NEUMANN, Rosane. Uma Alemanha em miniatura: o projeto de imigração e colonização étnico particular da colonizadora Meyer no noroeste do Rio Grande do Sul (1897-1932). Tese (Doutorado) - Pontifícia Universidade Católica do Rio Grande do Sul, Porto Alegre, 2009.

PESAVENTO, Sandra. A burguesia gaúcha: dominação do capital e disciplina do trabalho (RS 1889-1930). Porto Alegre: Mercado Aberto, 1988.

PESAVENTO, Sandra. História da indústria sul-rio-grandense. Guaíba: Riocell, 1985.

POITIER, Jean-Pierre. The reception of the German Historical Schools among French economists (1857-1900). In: CARDOSO, José Luís; PSALIDOPOULOS, Michalis (Ed.). The German Historical School and European Economic Thought. London, New York: Routledg, 2016.

POSSAMAI, Zita. Colecionar e educar: o Museu Julio de Castilhos e seus públicos (19031925). Varia Historia, 30 (53), 2014.

SÁ, Mem de. Tempo de lembrar. Rio de Janeiro: José Olympio, 1981.

SCHOBER, Hugo; SCHULZE, Eduard Otto. Grundriss der Volkswirtschaftslehre. 6. Auflage. Leipzig: Weber, 1905. (Exemplar da Facculdade de Direito da UFRGS, Seção de Obras Raras)

SCHWARCZ, Lilia. O espetáculo das raças: cientistas, instituições e questão racial no Brasil, 1870-1930. São Paulo: Companhia das Letras, 1993.

SIMCH, Francisco Rodolpho. Programa de economia social. Porto Alegre: Barcellos \& C.-Livraria do Globo, 1912. 
SIMCH, Francisco Rodolpho. Noções elementares de mineralogia e geologia. Obra adaptada aos cursos secundarios do Brasil. Porto Alegre: Barcellos, Bertaso e Cia, 1923.

SIMCH, Francisco Rodolpho. Programa de economia social - economia pura e política econômica. 2. ed. Porto Alegre: Livraria do Globo, 1931.

SIMCH, Francisco Rodolpho. Programa de economia social - economia pura e política econômica. 3. ed. Porto Alegre: Livraria do Globo, 1934.

SPONCHIADO, Breno. O Positivismo e a colonização do norte do Rio Grande do Sul. 2000. Dissertação (Mestrado) - Pontifícia Universidade Católica do Rio Grande do Sul, Porto Alegre, 2000.

STREISSLER, Erich. Rau, Hermann and Roscher: Contributions of German Economics around the Middle of the Nineteenth Century. The European Journal of the History of Economic Thought, 8 (3), 2001.

TRIBE, Keith. Governing Economy: The Reformation of German Economic Discourse 17501840. Cambridge: CUP, 1988.

\section{Sobre os autores}

Luiz Felipe Bruzzi Curi - luizfelipelfbc@gmail.com

Centro de Desenvolvimento e Planejamento Regional, Faculdade Ciências Econômicas, Universidade Federal de Minas Gerais, Belo Horizonte, Minas Gerais, Brasil.

ORCID: https://orcid.org/0000-0001-6477-1507.

Pedro Hoeper Dacanal-pedro.hoeper@gmail.com

Instituto de Ciências Sociais, Universidade de Lisboa, Lisboa, Portugal.

ORCID: https://orcid.org/0000-0003-3904-1646.

\section{Sobre 0 artigo}

Recebido em 11 de maio de 2018. Aprovado em 17 de dezembro de 2018. 